\title{
First in situ measurement of the vertical distribution of ice volume in a mesospheric ice cloud during the ECOMA/MASS rocket-campaign
}

\author{
M. Rapp ${ }^{1}$, I. Strelnikova ${ }^{1}$, B. Strelnikov ${ }^{1}$, R. Latteck ${ }^{1}$, G. Baumgarten ${ }^{1}$, Q. Li ${ }^{1}$, L. Megner $^{2}$, J. Gumbel $^{2}$, \\ M. Friedrich ${ }^{3}$, U.-P. Hoppe ${ }^{4}$, and S. Robertson ${ }^{5}$ \\ ${ }^{1}$ Leibniz-Institute of Atmospheric Physics, Kühlungsborn, Germany \\ ${ }^{2}$ Department of Meteorology, Stockholm University, Stockholm, Sweden \\ ${ }^{3}$ Institute of Communication Networks and Satellite Communications, Graz University of Technology, Austria \\ ${ }^{4}$ Norwegian Defence Research Establishment (FFI), Kjeller, Norway \\ ${ }^{5}$ Department of Physics, University of Colorado, Boulder, CO, USA
}

Received: 13 October 2008 - Revised: 16 January 2009 - Accepted: 23 January 2009 - Published: 16 February 2009

\begin{abstract}
We present in situ observations of mesospheric ice particles with a new particle detector which combines a classical Faraday cup with the active photoionization of particles and subsequent detection of photoelectrons. Our observations of charged particles and free electrons within a decaying PMSE-layer reveal that the presence of charged particles is a necessary but not sufficient condition for the presence of PMSE. That is, additional requirements like a sufficiently large electron density - which we here estimate to be on the order of $\sim 100 \mathrm{~cm}^{-3}$ - and the presence of small scale structures (commonly assumed to be caused by turbulence) need to be satisfied. Our photoelectron measurements reveal a very strong horizontal structuring of the investigated ice layer, i.e., a very broad layer $(82-88 \mathrm{~km})$ seen on the upleg is replaced by a narrow layer from $84.5-86 \mathrm{~km}$ only $50 \mathrm{~km}$ apart on the downleg of the rocket flight. Importantly, the qualitative structure of these photoelectron profiles is in remarkable qualitative agreement with photometer measurements on the same rocket thus demonstrating the reliability of this new technique. We then show that the photoelectron currents are a unique function of the ice particle volume density (and hence ice mass) within an uncertainty of only $15 \%$ and we derive corresponding altitude profiles of ice volume densities. Derived values are in the range $\sim 2-$ $8 \times 10^{-14} \mathrm{~cm}^{3} / \mathrm{cm}^{3}$ (corresponding to mass densities of $\sim 20$ $80 \mathrm{ng} / \mathrm{m}^{3}$, and water vapor mixing ratios of $3-12 \mathrm{ppm}$ ) and are the first such estimates with the unique spatial resolution of an in situ measurement.
\end{abstract}

Correspondence to: M. Rapp

(rapp@iap-kborn.de)
Keywords. Atmospheric composition and structure (Aerosols and particles; Middle atmosphere - composition and chemistry; Instruments and techniques)

\section{Introduction}

Mesospheric ice clouds form in the extreme environment of the cold summer mesopause and are routinely observed as noctilucent clouds (when observed from the ground) or polar mesospheric clouds (when observed from space) by optical means or as very strong radar echoes known as polar mesosphere summer echoes (e.g. Thomas, 1991; Lübken, 1999; Rapp and Lübken, 2004). These clouds have recently obtained considerable scientific interest because of their potential role as indicators of mesospheric processes covering several areas of atmospheric physics such as gravity wave dynamics, hemispheric differences, cross-equatorial coupling, and long term changes (e.g. Witt, 1962; Bailey et al., 2007; Karlsson et al., 2007; Thomas et al., 1989; DeLand et al., 2007; Baumgarten et al., 2008). In order to draw conclusions on any of these processes based on observations of cloud properties (such as brightness distributions etc.), a firm understanding of the relevant microphysical processes is obviously an important prerequisite. However, a recent review of our current understanding of these processes reveals that there are important open questions regarding fundamental issues such as the nucleation process, the saturation vapor pressure of ice under mesospheric conditions, the shape of the particle size distribution, and the shape of the particles (Rapp and Thomas, 2006). Hence, dedicated studies of

Published by Copernicus Publications on behalf of the European Geosciences Union. 
microphysical properties of these clouds both in the laboratory and in the field are urgently needed.

As one such attempt, the combined ECOMA/MASS sounding rocket campaign was conducted in August 2007 from the North-Norwegian Andøya Rocket Range. ECOMA stands for "Existence and Charge state Of meteoric smoke particles in the Middle Atmosphere" and is an European sounding rocket program led by the Leibniz-Institute of Atmospheric Physics (IAP) in Germany and the Norwegian Defence Research Establishment (FFI) with contributions from Sweden, Austria and the US. Within this program three sounding rocket campaigns comprising six rocket launches were carried out in 2006, 2007 and 2008 with the prime scientific objective of studying meteor smoke particles in the middle atmosphere and their relation to mesospheric ice clouds. Initial results of the first campaign in September 2006 are presented in Rapp and Strelnikova (2009) and Strelnikova et al. (2009), respectively. In 2007, the ECOMA campaign was combined with the US-American MASS (Mesospheric Aerosol Sampling Spectrometer) campaign which was led by the University of Colorado in Boulder (see Robertson et al., 2009, for details). In the current paper we report about measurements of mesospheric ice particles with the new ECOMA-particle detector and derive high resolution profiles of ice particle volume density (and mass), radii and number densities. In Sect. 2, we give an overview of the experimental techniques used for this study. Corresponding results from ground-based and in situ instruments are presented in Sect. 3, and the derivation of microphysical parameters from these measurements is then presented in Sect. 4, followed by a discussion in Sect. 5. Finally, our results are summarized in Sect. 6.

\section{Methods of observations}

The ECOMA/MASS sounding rocket campaign was supported by ground-based measurements with the ALWINradar, the ALOMAR RMR lidar and with the EISCAT VHF and UHF radars.

The ALOMAR wind (ALWIN)-radar and the ALOMAR RMR-lidar are two of the prime instruments of the ALOMAR observatory located in close vicinity to the Andøya Rocket Range at $69.3^{\circ} \mathrm{N}$ and $16^{\circ} \mathrm{E}$. The ALWIN-radar is a phased array consisting of 144 Yagi-antennas operating at a frequency of $53.5 \mathrm{MHz}$ and has been extensively used for the study of polar mesosphere summer echoes (PMSE) over the past $\sim 10$ years (Latteck et al., 1999; Bremer et al., 2006; Latteck et al., 2007). During the launch window, the radar was run in a special mode to sequentially measure $50 \mathrm{~s}$ in the vertical, $50 \mathrm{~s}$ tilted $7^{\circ}$ to the North-West (which is the direction of the rocket launches), $50 \mathrm{~s}$ tilted $14^{\circ}$ to the North-West, and then starting all over again. The ALOMAR Rayleigh/Mie/Raman (RMR) lidar measures relative density profiles and particle (aerosol) properties in the stratosphere and mesosphere and has been described in detail by von Zahn et al. (2000). Throughout the noctilucent cloud (NLC) season (1 June to 15 August) the lidar is held operational $24 \mathrm{~h}$ a day to take advantage of even short measurements permitted by the weather conditions. A recent review of corresponding results is presented in Baumgarten et al. (2008). For the ECOMA/MASS campaign in 2007, the ALWINradar and the ALOMAR RMR-lidar were the most important ground-based instruments indicating the presence or absence of mesospheric ice clouds and were hence invaluable for the identification of the launch criteria of the sounding rockets.

The EISCAT UHF and VHF ( 930 and $224 \mathrm{MHz}$ ) incoherent scatter radars are located at Troms $\varnothing\left(69^{\circ} \mathrm{N}, 19^{\circ} \mathrm{E}\right)$ which is $130 \mathrm{~km}$ away from the launch site. During the launch window of the ECOMA 2007 campaign the radars were both run using an alternating code called "arc-dlayer" which is a further development of another low altitude modulation described in detail in Turunen et al. (2002). These measurements provided real time information of electron number densities and PMSE in the altitude range from 60 to $140 \mathrm{~km}$ with a height resolution of $300 \mathrm{~m}$. Details about the EISCAT VHF and UHF radars can be found in Baron (1986) and Folkestad et al. (1983), respectively.

The ECOMA sounding rocket carried a total of eight different instruments for the characterization of mesospheric aerosol particles, the ambient D-region plasma, payload charging effects, and properties of the neutral gas such as density, temperature and turbulence parameters. A detailed description of most instruments can be found in Strelnikova et al. (2009). In 2007, the ECOMA payload also carried a NLC photometer from the University of Stockholm for the optical in situ detection of mesospheric ice particles (e.g. Gumbel et al., 2001). The design of this photometer is described in detail in the accompanying paper by Megner et al. (2009).

The prime in situ instrument for this article is the ECOMA particle detector which is mounted on the front deck of the ECOMA payload (Rapp and Strelnikova, 2009). In short, the ECOMA particle detector is a Faraday cup with two biased grids to shield the cup against ambient electrons and positive ions, similar to the one first used by Havnes et al. (1996). Heavy particles pass through these biased grids because of their large kinetic energy and - if they carry some charge - produce a current which can be measured by a sensitive electrometer. Note, that neutral particles cannot be detected by this method, and neither can small aerosol particles with radii less than $\sim 3 \mathrm{~nm}$ reach the detector electrode because of aerodynamical effects (Horányi et al., 1999; Rapp et al., 2005; Hedin et al., 2007). To detect particles of a broad size range and independent of their charge state, however, the Faraday cup is combined with a xenon flash lamp for the active photoionization of particles and the subsequent detection of photoelectrons. The detector has two data channels, one for the direct Faraday Cup measurement and one for the detection of photoelectrons excited by the UV-photons of the 


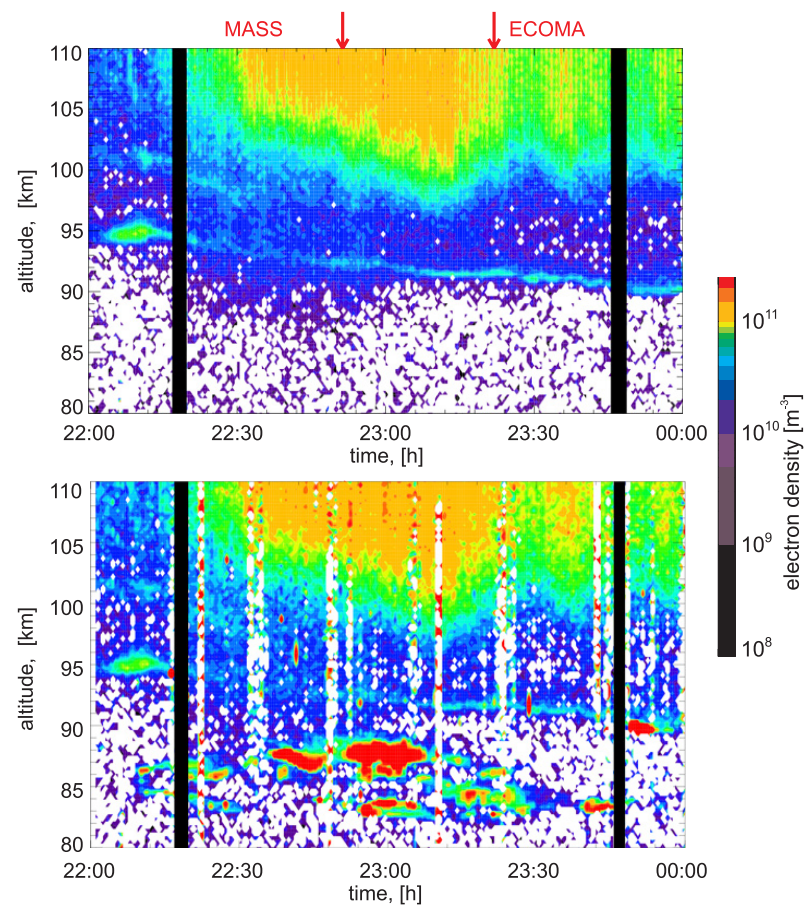

Fig. 1. Electron densities derived from measurements with the EISCAT UHF- (upper panel) and VHF-radar (lower panel). Note that the very strong signals seen in the VHF-radar between 80 and $90 \mathrm{~km}$ may not be interpreted as electron densities but origin from coherent scatter owing to PMSE. The times of the MASS and ECOMA rocket launches are indicated by red vertical arrows at the top of the figure. Black vertical stripes indicate times when the measurements were interrupted.

xenon flash lamp. More details about the detector and first results regarding the detection of meteor smoke particles from a rocket flight in September 2006 can be found in Rapp and Strelnikova (2009) and Strelnikova et al. (2009), respectively.

For the current paper we further use data from the Faraday rotation experiment yielding absolute electron number densities (e.g. Friedrich et al., 2006). Further details regarding the plasma measurements onboard the ECOMA payload are presented in the companion paper by Brattli et al. (2009).

\section{Atmospheric observations}

The MASS and ECOMA sounding rockets were launched on 3 August 2007, at 22:52 UT and 23:22 UT, respectively. Figure 1 shows the observations with the EISCAT UHFand EISCAT VHF-radar during the night of these rocket launches. Starting from $\sim 22: 15$ UT, some weak particle precipitation occurred and created enhanced electron densities in the E-region. D-region electron densities were only slightly enhanced during the most intense phase of this precipitation event, i.e., from $\sim 22: 15$ UT until $\sim 23: 45$ UT. Dur-

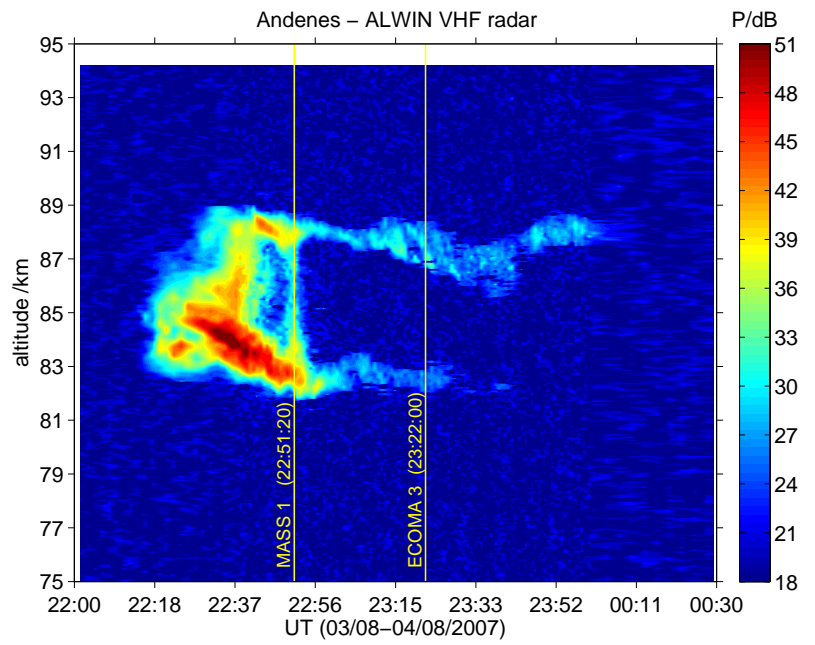

Fig. 2. Power values (colour coded) observed with the ALWIN VHF-Radar as a function of altitude and time on 3 August 2007. The two vertical yellow lines indicate the times of the MASS and ECOMA-03 rocket launches at 22:52 UT and 23:22 UT, respectively.

ing this period, the EISCAT VHF-radar also recorded a weak and rather patchy PMSE at altitudes between 83 and $88 \mathrm{~km}$. The local ALWIN-measurements for the same period are shown in Fig. 2. At the time of the precipitation onset seen by the EISCAT radars, ALWIN recorded the onset of an initially rather strong PMSE covering in its maximum phase at around 22:30 UT the entire altitude range from $82-89 \mathrm{~km}$. The MASS payload was launched right after this maximum phase whereas the ECOMA payload flew at the time when the PMSE had already decayed significantly. I.e., after about 22:50 UT, the PMSE signal disappeared more or less completely between 84 and $86 \mathrm{~km}$ and only two rather narrow and weak PMSE layers remained at $82-83$ and $87-88 \mathrm{~km}$.

At the same time, the ALOMAR RMR-lidar was able to measure under conditions of scattered clouds until about 14 min before the ECOMA launch. Afterwards, the cloud cover prevented any further optical measurements until the morning hours. Nonetheless, during the phases of observations, the RMR-lidar succeeded detecting a rather broad NLC-layer covering the altitude range from $82-86 \mathrm{~km}$ at its maximum (see Fig. 3). In addition, photographic observations with an NLC-camera located at Trondheim $\left(63.4^{\circ} \mathrm{N}\right.$, $10,4^{\circ} \mathrm{E}$ ) confirmed the large scale presence of NLC also during the ECOMA launch at 23:22 UT. More details about the NLC-display of this night taking into account lidar observations at different Scandinavian stations, NLC-photography, and satellite observations are presented in the companion paper by Baumgarten et al. (2009).

In Fig. 4 we present an overview of the measurements with the ECOMA particle detector in comparison to the ALWIN radar observations and absolute electron density 


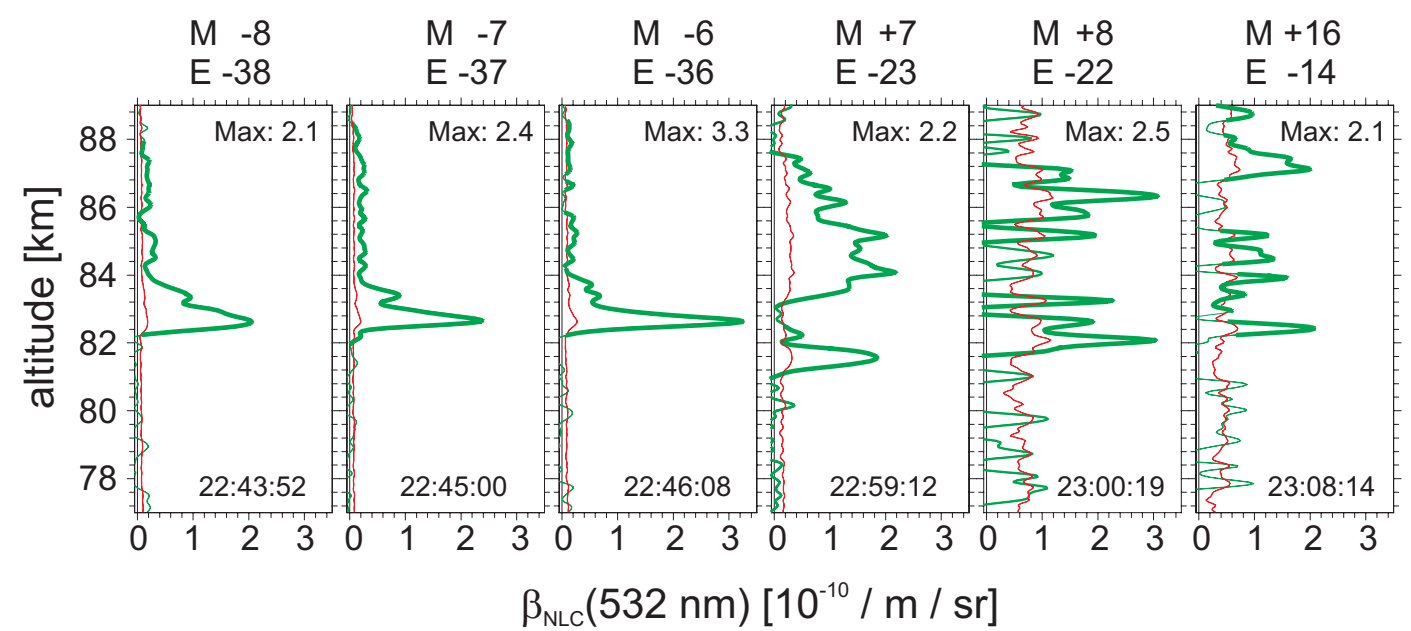

Fig. 3. Sequence of altitude profiles of backscatter coefficients derived from observations with the ALOMAR RMR lidar. The labels over each of the panels indicate the relative time in minutes to the MASS (M) and ECOMA (E) launches. Thin green lines show the actual measurements, whereas red lines indicate the noise level. Thick green lines indicate altitude-regions with continuous signals which exceed the noise level by at least one standard deviation and which are hence identified as NLC.
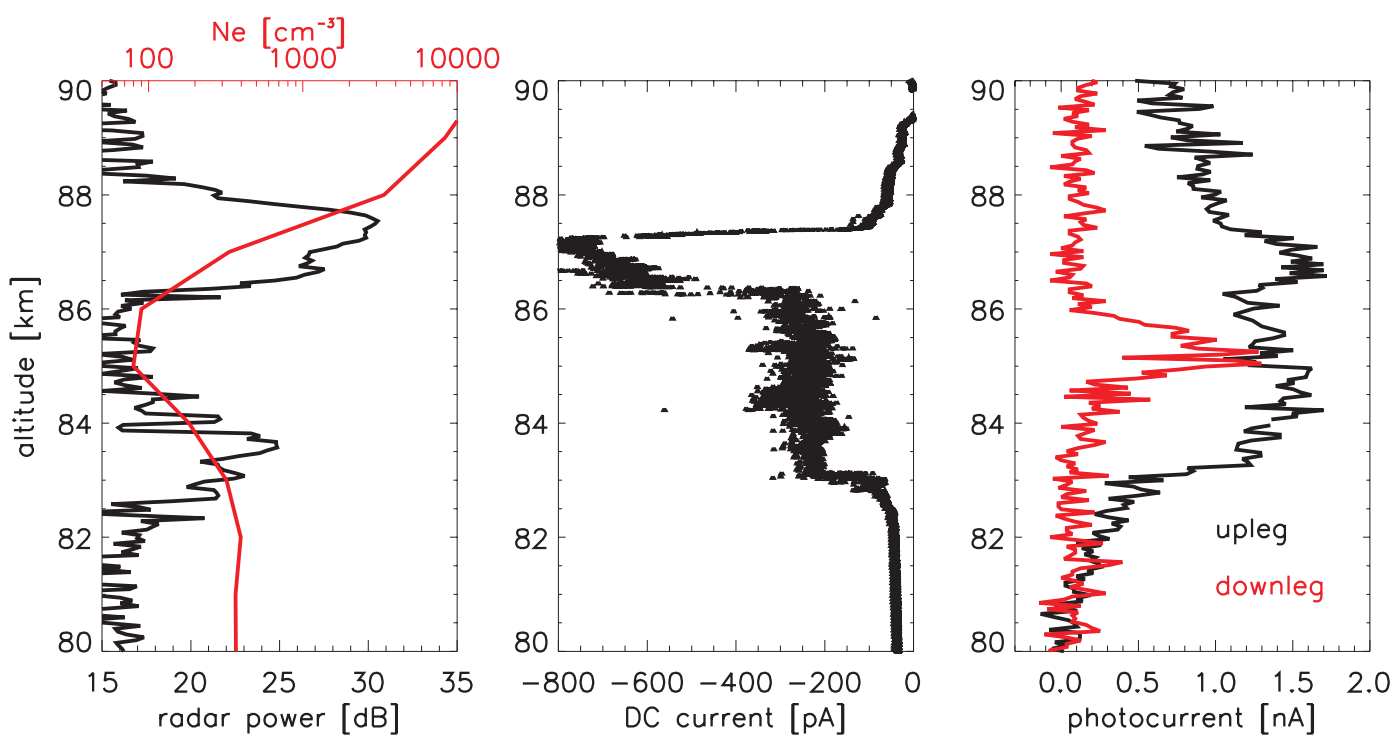

Fig. 4. Overview of measurements with the ECOMA-particle detector in comparison to ALWIN VHF-radar measurements of PMSE and absolute electron densities from the Faraday propagation experiment (left panel). Mid panel: DC-current measured by the ECOMA-particle detector owing to charged particles reaching the detector electrode inside the Faraday cup. Right panel: Photoelectron currents recorded by the ECOMA-particle detector on upleg (black line) and downleg (red line) of the rocket flight.

measurements with the Faraday rotation experiment. In the left panel of this figure, ALWIN-measurements with the $7^{\circ}$ North-West-beam are shown at the time of the rocket launch. Note that the rocket passed through the edge of the volume illuminated by this beam on the upleg part of the rocket trajectory. In the same panel, we have overplotted the electron density measurements from the Faraday rotation experiment. Interestingly, this shows that the PMSE disappeared exactly at the altitudes where the electron density was significantly diminished. This is in line with results of a previous study by Rapp et al. (2002) who found that PMSE require a minimum ambient electron number density of a few hundred electrons $/ \mathrm{cm}^{3}$. Hence, it appears that the decaying D-region ionization was - at least partly - responsible for the decay of the PMSE-layer. 

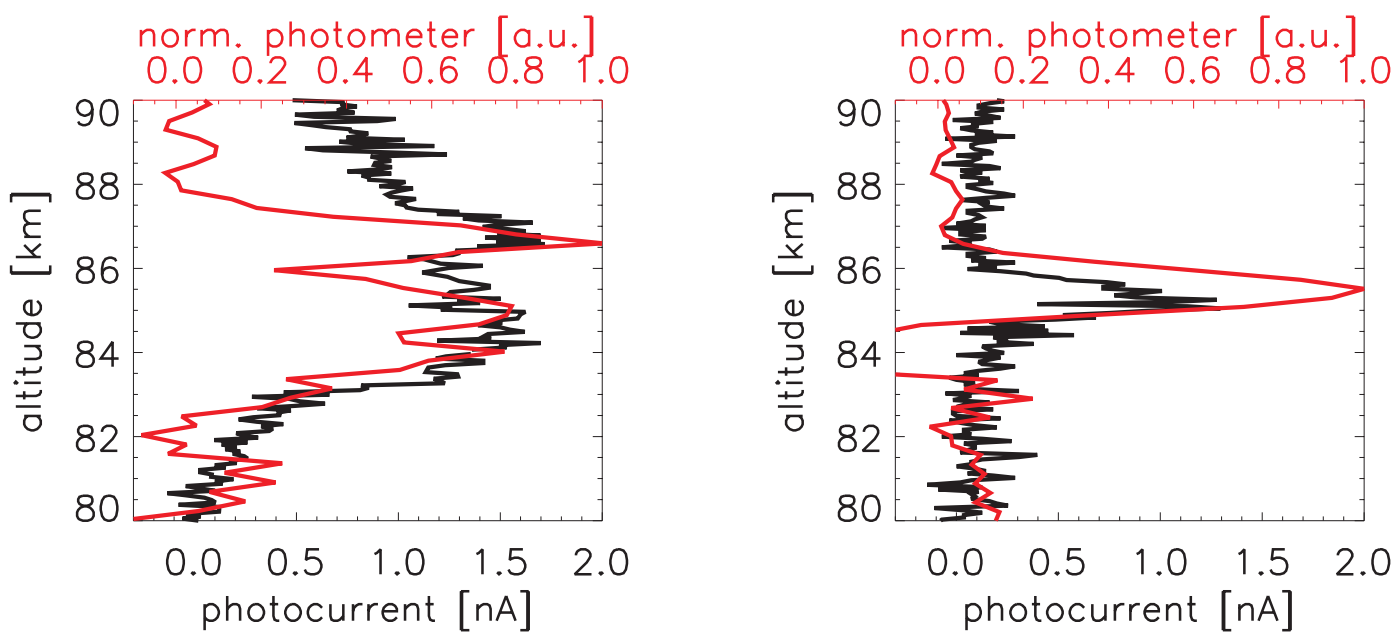

Fig. 5. Photoelectron currents recorded by the ECOMA-particle detector on upleg (left panel) and downleg (right panel) compared to photometer measurements indicating the presence of "visible" ice particles (red lines), i.e., ice particles with radii in excess of $\sim 20 \mathrm{~nm}$. Note that the photometer profiles shown here are derived by taking the vertical derivative of a signal which is the integral of the scattering from all particles and molecules along the line of sight of the instrument. E.g., as the instrument passes through the cloud from above (as is the case during the downleg, see right panel), this integral signal should steadily increase because more and more particles are along the line of sight (the rocket is spin-stabilized and the photometer is pointing upwards). Hence, the photometer signal is expected to show a continuous increase when moving through the cloud and the derivative should reveal the cloud as a pronounced layer of positive values only. On top of the vertical motion, however, the rocket is also spinning such that the photometer with a field of view at some angle to the rocket axis scans different horizontal parts of the cloud. If the cloud is strongly inhomogeneous, it may happen that the integral scattering signal could actually decrease during the rocket's descent through the cloud because the photometer sees a dimmer patch at some horizontal location than at another location. In consequence, the differentiated brightness profile can turn negative as shown here at about $84 \mathrm{~km}$. This feature hence indicates pronounced inhomogeneities in the cloud layer. See Megner et al. (2009) for more details.

Next, the ECOMA particle measurements are shown in the mid panel (DC-measurements, $\mathrm{DC}=$ direct current) and right panel (photocurrents), respectively. Turning first to the DCmeasurements showing the slowly varying currents recorded with the classical Faraday cup-part of the ECOMA instrument, we see that net negatively charged particles are observed in the entire altitude range from $82-88 \mathrm{~km}$, i.e., also at those altitudes where the PMSE had already disappeared. This clearly shows that the presence of charged ice particles alone is not a sufficient condition for the existence of PMSE. Rather, PMSE also require a mechanism creating small scale structures at the radar Bragg scale which is commonly assumed to be neutral air turbulence in combination with these charged aerosol particles (e.g. Kelley et al., 1987; Rapp and Lübken, 2004) and sufficient ionization, as suggested by the comparison of the PMSE with the electron densities discussed above. For a detailed analysis of small scale structures in neutrals and charged particles observed during the ECOMA rocket flight we refer to the companion paper by Strelnikov et al. (2009).

Furthermore, it is interesting to note that the upper PMSE layer coincides with a rather pronounced layer of net negatively charged particles which was also observed about 30 min before the ECOMA launch by the MASS instrument (Robertson et al., 2009, their Figs. 6 and 7, compare to net current in channel 4). In comparison, the photoelectron currents recorded in the second data channel of the ECOMA particle detector show a similar but slightly less pronounced vertical structure, i.e., the upper maximum is not as pronounced as in the DC-channel. In the same panel, we also show photoelectron currents measured on the downleg part of the rocket flight, where direct Faraday cup measurements are not available because the instrument is in the payload wake. As explained in Rapp and Strelnikova (2009), photoelectron currents recorded during this part of the rocket flight are in fact of high data quality and can be used for comparing structures seen on upleg and downleg. The striking result here is the very large difference seen between the two altitude profiles (in black for upleg and in red for downleg). While on upleg, the detected layer covered the entire altitude range from 82 to $90 \mathrm{~km}$, the measurements on downleg - which were made at a horizontal distance of about $50 \mathrm{~km}$ - reveal a rather narrow layer between 84.5 and $86 \mathrm{~km}$.

Fortunately, we are in the lucky situation of being able to compare our measurements with this new technique relying on the photoionization of the particles to a well proven technique, i.e., NLC-photometry. The results of a corresponding comparison for both upleg and downleg are presented in Fig. 5. While a direct match between both signals is not expected since the photoelectron currents are 


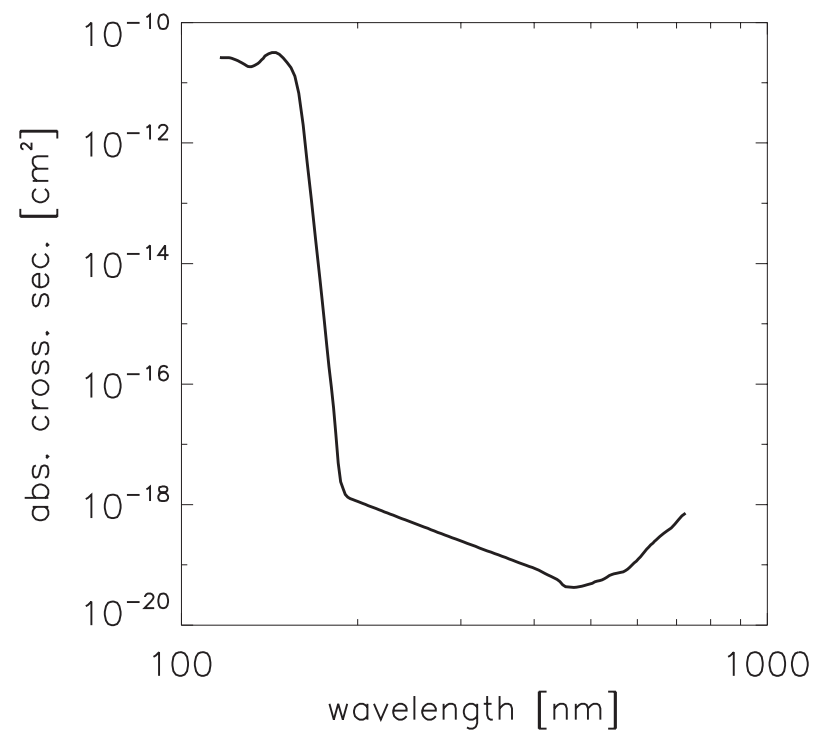

Fig. 6. Absorption cross section as a function of wavelength for ice particles of $30 \mathrm{~nm}$ radius using complex refractive indices from Warren (1984).

roughly proportional to the volume of the ice particles (see Sect. 4 for details) whereas the photometer measurements are roughly proportional to the sixth power of the ice particle radius and because the photometer has a slightly different field of view (and hence scans a slightly different atmospheric volume), the similarity between both measurements is in fact striking and clearly underlines the reliability of the ECOMA photoelectron-measurements. In summary, our observations imply a rather pronounced inhomogeneity of the cloud which is further supported by independent measurements onboard ECOMA and the MASS payload (Megner et al., 2009; Robertson et al., 2009) and by the lidar observations presented in Baumgarten et al. (2009) who observed pronounced differences in NLC layer structure on spatial scales of $20 \mathrm{~km}$.

\section{Derivation of microphysical parameters}

In this section we describe a methodology to derive ice volume densities as well as number densities and particle radii (assuming monodisperse particles) from the measurements with the ECOMA particle detector. For the derivation of these microphysical parameters we start by recalling a result from the study by Rapp and Strelnikova (2009), namely that the photoelectron current recorded by the ECOMA instrument can be written as

$$
\begin{aligned}
I= & \left(\int_{r_{\min }}^{\infty} \int_{2,5 \mathrm{~cm}}^{v_{e} \cdot \Delta t} \int_{110 \mathrm{~nm}}^{h c / W_{p}} \frac{d N_{p}}{d r_{p}} \cdot \frac{d F}{d \lambda} \cdot \sigma\left(r_{p}, \lambda\right)\right. \\
& \left.\cdot P \cdot d r_{p} \cdot d l \cdot d \lambda\right) \cdot \frac{e}{\Delta t}
\end{aligned}
$$

where $e$ is the electron charge, $r_{\min }$ is the minimum assumed size of the particles in a particle size distribution, $v_{e}$ is the velocity of a photoelectron, $\Delta t=10 \mu \mathrm{s}$ is the sampling interval during which photoelectrons are recorded, $h$ is Planck's constant, $c$ is the speed of light, and $W_{p}$ is the threshold energy for photoionization/photodetachment of a particle, i.e., the workfunction or electron affinity of the corresponding material. $d F / d \lambda$ is the number of photons per wavelength interval emitted in one flash, and $l$ is the distance from the particle detector. $P=S /\left(4 \pi l^{2}\right)$ is the probability that the photoelectron is emitted towards the detector electrode with area $S$. $d N_{p} / d r_{p}$ is the number density of particles per size interval $d r_{p}$, and $d l$ and $d \lambda$ are the length and wavelength elements over which the integrations above are carried out. Note that the integration over the wavelength $\lambda$ starts at $110 \mathrm{~nm}$ because of the transmission properties of the $\mathrm{MgF}_{2}$-window of the Xe-flashlamp.

Finally,

$\sigma\left(r_{p}, \lambda\right)=\pi r_{p}^{2} \cdot Q_{\mathrm{abs}}\left(r_{p}, \lambda, n(\lambda), k(\lambda)\right) \cdot Y$

is the photoionization/photodetachment cross sections of particles with radius $r_{p}$ at photon wavelength $\lambda$. The cross sections are estimated using Mie-theory. In Eq. (2), $Q_{\text {abs }}$ is the Mie absorption efficiency which we calculated using the publicly available Mie-code from the textbook by Bohren and Huffman (1983), $n$ and $k$ are the real and imaginary parts of the refractive index of the particle material, and $Y$ is the quantum yield for photoemission/photodetachment.

Applied to ice particles, we are in the favorable position that most of the material-specific parameters in the above equations are known. I.e., refractive indices in the relevant wavelength range can be found in the tabulation by Warren (1984) and laboratory data of the photoelectron yield of low temperature ice is available from Baron et al. (1978). Note that we will discuss the potential influence of metallic impurities on the photoelectric yield in detail in Sect. 5. The question, whether the workfunction $(8.7 \mathrm{eV}$, see Baron et al., $1978)$ or the electron affinity $(0.8 \mathrm{eV}$, see do Couto et al., 2006) should be used, is fortunately also not a problem. The reason for this can be found in the wavelength dependence of the absorption cross section. In Fig. 6 we have plotted the latter for a $30 \mathrm{~nm}$ ice particle for wavelengths from $100 \mathrm{~nm}$ to $1 \mu \mathrm{m}$, corresponding to energies between $\sim 12 \mathrm{eV}$ and $1 \mathrm{eV}$. This figure clearly shows that - in the wavelength range considered here - ice basically does not absorb at all at wavelengths larger than about $150 \mathrm{~nm}$ (energies below about $8 \mathrm{eV}$ ). Hence, it only makes a negligible difference whether the wavelength integration is carried out starting from $0.8 \mathrm{eV}$ or starting from $8.7 \mathrm{eV}$.

The starting point of our retrieval is now the fact that at least in the Rayleigh-limit, the absorption cross section in Eq. (2) is expected to be proportional to the particle volume (e.g. Bohren and Huffman, 1983). In order to see whether this relation is still valid for the wavelengths of our rocket experiment and radii expected in mesospheric ice clouds, we 


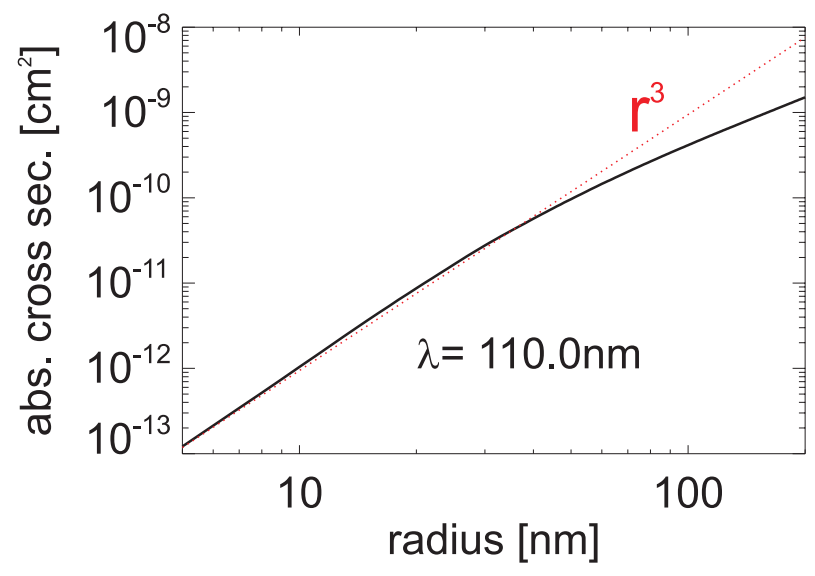

Fig. 7. Absorption cross section of ice particles as a function of radius for a wavelength of $110 \mathrm{~nm}$ (black line). The red line indicates the Rayleigh limit in which the absorption cross section is proportional to the volume of the particles.

have calculated the ice particle absorption cross section as a function of ice particle radius for the shortest wavelength emitted by the xenon flashlamp of the ECOMA detector, i.e., $110 \mathrm{~nm}$. The result of this calculation is shown in Fig. 7. In the same figure we have also plotted a line proportional to the particle volume for comparison. This figure shows that the absorption cross section closely follows the volumedependence up to radii of about $40 \mathrm{~nm}$, after which some deviation is observed. Note, however, that the dependence shown in Fig. 7 shows the worst case scenario, since the calculation was carried out for one single wavelength and monodisperse particles. In reality, however, we both have to take into account the full spectrum of our xenon-flashlamp and a particle size distribution which is known to smooth out variations in the Mie-cross sections (e.g. Rapp et al., 2007). Hence, in order to find out whether we may still infer ice volume densities from our photoelectron measurements we have performed a large number of simulations. We assumed two different particle size distribution types, namely a Gaussian distribution and a lognormal distribution, since these are generally assumed in NLC studies (see Rapp and Thomas, 2006, for a detailed discussion). For each of these distributions we varied the distribution parameters in a wide range of values and computed the expected photoelectron current and the corresponding ice particle volume density for each of these combinations. For the case of a Gaussian distribution we varied the mean radius between 10 and $100 \mathrm{~nm}$ in steps of $5 \mathrm{~nm}$, and the distribution width from $5,10,15$ to $20 \mathrm{~nm}$. For the lognormal distribution, we varied the median radius in the same range as above and assumed distribution widths of 1.1, 1.2, 1.4, 1.6 and 1.8. Finally, for all these different distributions we assumed particle number densities between 1 and 2000 particles $/ \mathrm{cm}^{3}$ with a step of $1 / \mathrm{cm}^{3}$. The result of these calculations is presented in Fig. 8. This figure clearly

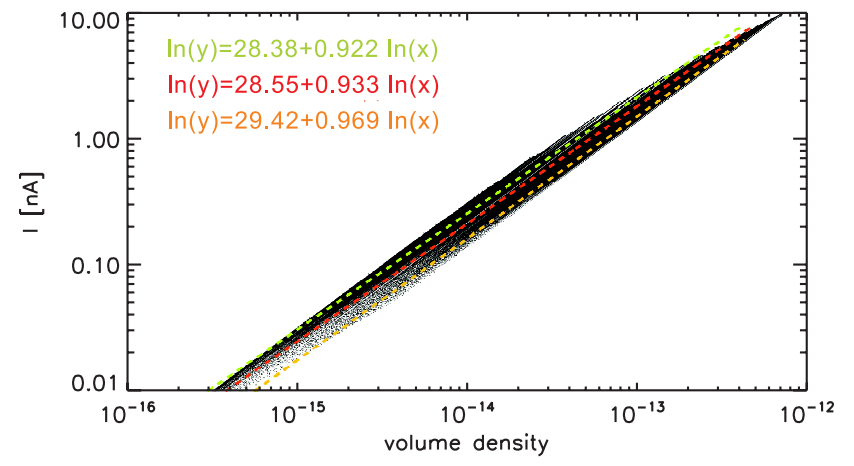

Fig. 8. Theoretically expected photoelectron currents to be detected by the ECOMA particle detector as a function of ice particle volume density (in $\mathrm{cm}^{3} / \mathrm{cm}^{3}$ ). Each black point corresponds to one calculation assuming either a Gaussian or lognormal size distribution for a large number of distribution parameters (see text for details). The colored dashed lines show fits of $\ln$ (current) versus $\ln$ (volume density). The red line shows the best fit to the data, and the yellow and green lines indicate corresponding standard deviations.

shows a robust dependence of the photoelectron current on the ice particle volume density even though the results do not show an ideal linear relation. Overplotted on the simulation results, we also show three lines, i.e., a best fit to the data (red line) along with its standard deviations (green and yellow line) indicating the uncertainty of the fit.

Using these fitting results, we are actually now in the situation to convert measured photoelectron currents to ice volume densities and their uncertainties. Corresponding profiles of the ice volume densities from upleg and downleg of the rocket flight are shown in Fig. 9. This figure shows that ice volume densities vary between $2 \pm 1$ and $8 \pm 2 \times 10^{-14} \mathrm{~cm}^{3} / \mathrm{cm}^{3}$ (corresponding to mass densities of $\sim 20-80 \mathrm{ng} / \mathrm{m}^{3}$, and water vapor mixing ratios of 3-12 ppm) with maximum values only about half as big on downleg as compared to upleg. These values lie within the range of independent estimates from the SOFIE instrument and lidar observations at ALOMAR, even though we also note that our maximum value appears to be a little bit on the large side of values reported in Baumgarten and Fiedler (2008) and Hervig et al. (2009). This impression is also confirmed by the fact that maximum values observed by SOFIE on the day of our rocket launch (but not exactly at the time and place of our measurements), never reach more than $\sim 50 \mathrm{ng} / \mathrm{m}^{3} \approx 50 \times 10^{-14} \mathrm{~cm}^{3} / \mathrm{cm}^{3}$ (Baumgarten et al., 2009). We will come back to this point in Sect. 5 .

Besides the absolute values mentioned above, we further find two things noteworthy: the first is the near constant volume density over an altitude range of almost five kilometers seen in the upper panel in Fig. 9. The other point is the extremely large variability from upleg to downleg (horizontal distance $50 \mathrm{~km}$ ) indicating that this ice cloud 

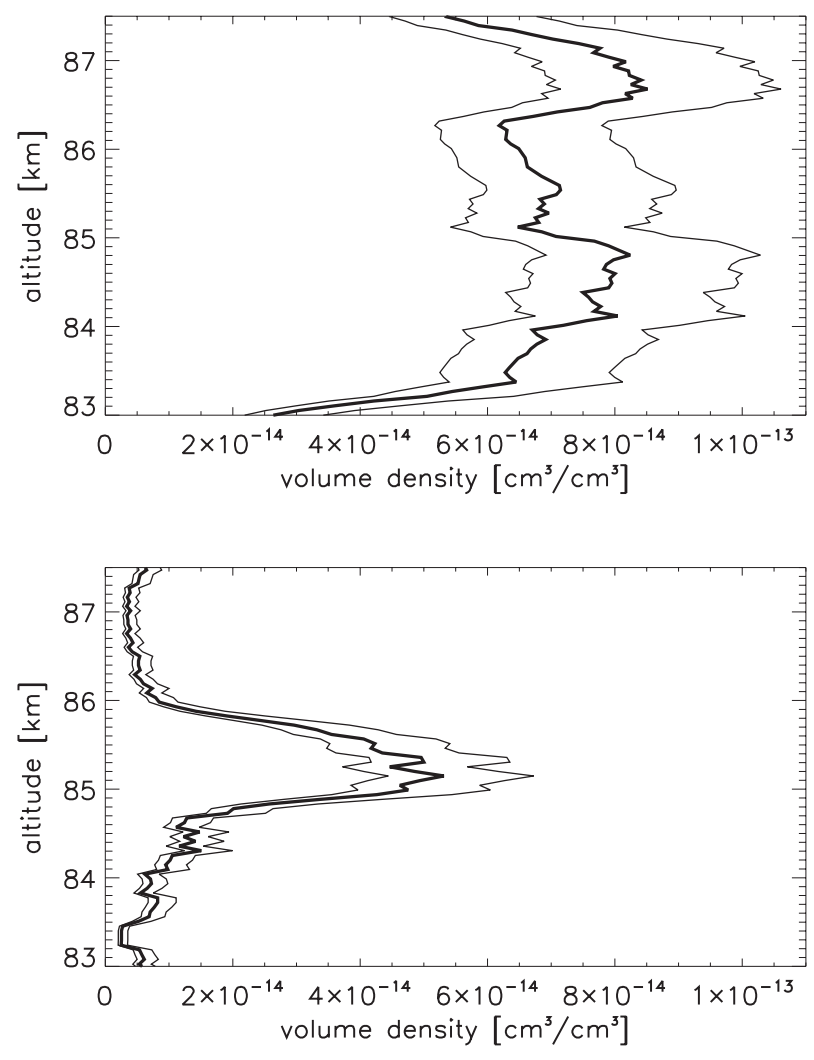

Fig. 9. Altitude profile of derived ice volume density (thick black line) with error bars (thin black lines). The upper panel shows results from the upleg part of the rocket flight whereas the lower panel shows corresponding results from downleg. Note that the volume densities indicated here can be easily converted to mass densities by multiplying the given numbers by an ice density of $0.93 \mathrm{~g} / \mathrm{cm}^{3}$.

was extremely inhomogeneous in agreement with photometer measurements onboard ECOMA, measurements on the MASS payload, and with lidar observations and NLC photography (Megner et al., 2009; Robertson et al., 2009; Baumgarten et al., 2009).

Finally, we have also tried to derive ice particle radii and number densities by combining the above photoelectron measurements with the direct Faraday cup measurements of the ECOMA instrument. Ignoring for the moment any secondary effects (e.g. Havnes and Næsheim, 2007) and also ignoring the fact that a current measurement like that of a simple Faraday cup can only measure net current (i.e., it will miss particles of opposite polarity and identical charge number density), the current shown in the middle panel in Fig. 4 can be easily converted to charge number densities making use of the simple relation

$$
I_{\mathrm{DC}}=e \cdot N_{p} Z_{p} \cdot S \cdot v_{r}
$$

where $e$ is the electron charge, $N_{p}$ is the number density of the particles, $Z_{p}$ is the number of elementary charges car-
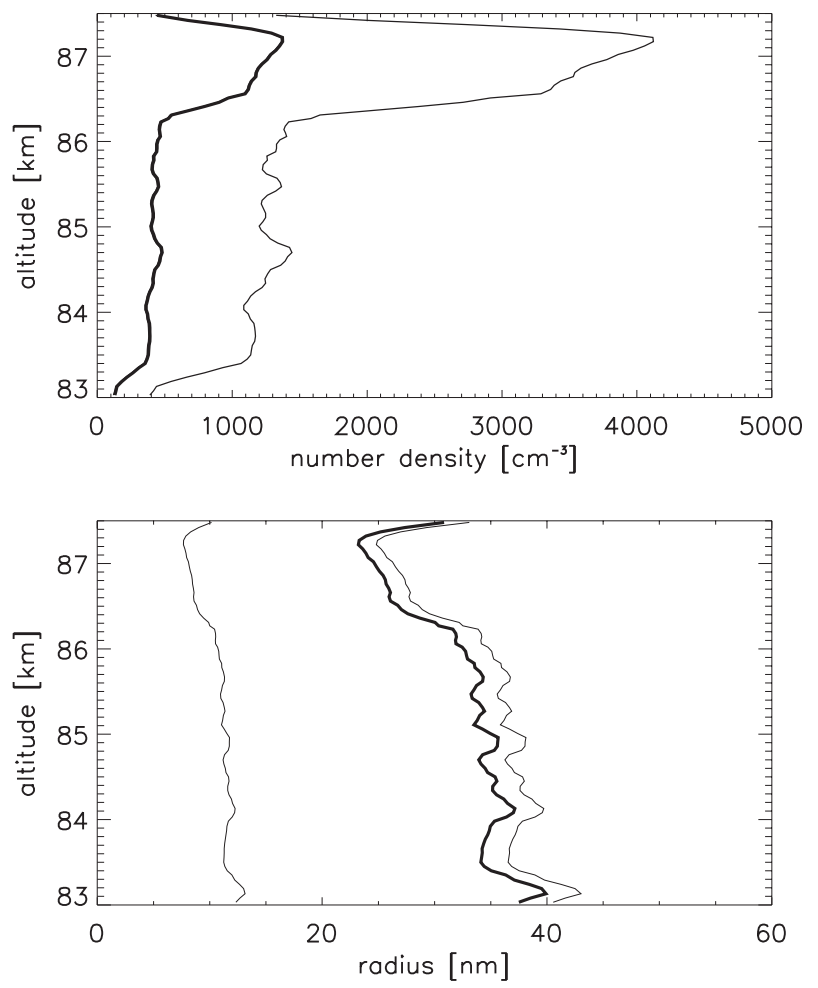

Fig. 10. Altitude profiles of ice particle number densities (assuming singly charged particles, upper panel, thick black line) and particle radii (assuming monodisperse particles, lower panel, thick black line) with corresponding uncertainties (thin black lines). Note that the very asymmetric uncertainty of the number density is due to the fact that the Faraday Cup could severely underestimate the particle number density because only net current can be measured, whereas the error to lower values is solely determined from the statistics of our data and is of the order of $5 \mathrm{~cm}^{-3}$. The uncertainty of the particle radii is due to the combined uncertainty of the ice volume density estimate and the number density estimate.

ried by a particle (with negative/positive values indicating negatively/positively charged particles), $S$ is the area of the detector electrode, and $v_{r}$ is the rocket velocity. Based on the charging model of Rapp and Lübken (2001) (see their Fig. 4) and taking into account that the ratio between particle charge number density and free electron number density was larger than $\sim 0.5$ in most of the altitude range considered here (see Fig. 4, right panel, and also Brattli et al., 2009) we further assume that the particles were only singly charged. The resulting altitude profile of the number density is shown in the upper panel of Fig. 10. This figure reveals that number densities were roughly constant at a level of $\sim 400 \mathrm{~cm}^{-3}$ up to about $86 \mathrm{~km}$ and then drastically increased to values between 1000 and $1400 \mathrm{~cm}^{-3}$ between 86 and $87.5 \mathrm{~km}$. Regarding the uncertainty of these numbers, the most severe point seems to be the fact that Faraday Cups can only measure the net charge, i.e., it will miss particles of opposite 
polarity but identical concentration. Robertson et al. (2009) report measurements with their aerosol mass spectrometer which is able to distinguish particles of different polarities from the MASS rocket flight $30 \mathrm{~min}$ before the ECOMAlaunch. This spectrometer has four different mass channels covering ice particles with radii $<0.5 \mathrm{~nm}, 0.5-1 \mathrm{~nm}, 1-2 \mathrm{~nm}$, and $>3 \mathrm{~nm}$ (i.e., all particles larger than $3 \mathrm{~nm}$ are detected in this channel). These measurements show that particles of both polarities co-exist in all mass channels. For the comparison to our ECOMA measurements, however, we have to keep in mind that a Faraday Cup can only measure ice particles being larger than $\sim 3 \mathrm{~nm}$ because of aerodynamical effects (Horányi et al., 1999; Rapp et al., 2005; Hedin et al., 2007). Hence, we should only compare our measurements to MASS measurements in their channel 4, i.e., covering particles with radii $>3 \mathrm{~nm}$. These measurements reveal that both polarities do co-exist, but that negative particles dominate over positive particles by about a factor of 2 and result - as in the case of ECOMA - in a layer of net negative particles. Hence, from this comparison, we may tentatively draw the conclusion that number densities derived from the Faraday Cup measurements could be underestimated by as much as a factor of three.

With these number densities, we may now finally also derive ice particle radii $r_{p}$ assuming monodisperse particles via the simple relation

$r_{p}=\left(\frac{3 V_{\text {ice }}}{4 \pi N_{p}}\right)^{\frac{1}{3}}$

where $V_{\text {ice }}$ is the volume density of ice. The finally resulting altitude profile of $r_{p}$ is shown in the lower panel of Fig. 10 . This reveals maximum radii of about $38_{-25}^{+3} \mathrm{~nm}$ at the bottom of the observed layer which slowly decrease to $\sim 33_{-23}^{+3} \mathrm{~nm}$ at $86 \mathrm{~km}$. Above $86 \mathrm{~km}$, a sudden further decrease to values of about $25_{-18}^{+2} \mathrm{~nm}$ within a few hundred meters only is observed, which is in line with the simultaneous sudden increase in particle number density.

\section{Discussion}

We now critically discuss our results in the scope of other independent measurements. First of all, we would like to point out that the results presented here are - to our knowledge - the first in situ measurements of the ice volume density/ice mass density in a mesospheric ice cloud. While measurements of the ice mass density have recently been reported from the SOFIE instrument onboard the AIM satellite (Hervig et al., 2009), and estimates of the volume density were recently provided by Baumgarten and Fiedler (2008) based on microphysical parameters inferred from three-wavelength lidar observations, we note that none of these previous measurements comes even close to the spatial resolution of the measurements presented here: while the
SOFIE measurements represent an average over a volume of $1.5 \mathrm{~km} \times 4.3 \mathrm{~km} \times 290 \mathrm{~km}$, the lidar measurements sample a rather small volume of only $10 \mathrm{~m}$ in diameter and $150 \mathrm{~m}$ in the vertical. However, in order to achieve reasonable signal to noise, the lidar measurements need to be integrated in time over $\sim 15 \mathrm{~min}$, which corresponds to an averaging of the sampled volume along the prevailing wind direction with an extent of about $45 \mathrm{~km}$ (assuming a typical mesospheric wind of $\sim 50 \mathrm{~m} / \mathrm{s}$ ). In contrast to this, the sampling volume of our rocket instrument is determined by the volume from which photoelectrons can be collected, which is conically shaped with an opening angle of $30^{\circ}$ extending less than $1 \mathrm{~m}$ in front of the rocket (Rapp and Strelnikova, 2009). The rocket measurement provides a real local snap shot of the situation within an ice cloud. Hence, the fact that volume densities derived from our measurements are at the maximum edge of values reported by SOFIE and the lidar measurements, could simply be the consequence of an integration of inhomogeneous clouds by these other techniques. In our case, this seems to be particularly plausible, since the rocket measurements themselves give clear evidence of a very strong inhomogeneity of the cloud, at least on spatial scales of tens of kilometers.

Nevertheless, we need to point out that there might actually be one process which might lead to an overestimate of the ice volume densities reported here. This deficiency could be due to our assumption of "clean" ice particles with no significant surface contamination for example by sodium atoms. Combining lidar observations of NLCs and the sodium layer, laboratory measurements, and atmospheric modeling, Plane et al. (2004) recently demonstrated that mesospheric ice clouds efficiently scavenge $\mathrm{Fe}$ atoms of meteoric origin from the gas phase. Similarly, other metal atom species like K and $\mathrm{Na}$ have also been found to be significantly depleted in the presence of mesospheric ice clouds (e.g. Witt et al., 1974; Lübken and Höffner, 2004; She et al., 2006; Fan et al., 2007). Motivated by these results, Vondrak et al. (2006b) recently investigated the effect of sodium impurities on the photoemission from ice in the laboratory, and found that a deposition of only 0.02 monolayers of sodium led to a dramatic increase of the photoemission from the ice film. However, they also found that the photoemission rate decayed rapidly in time and estimated a decay rate of $5 \times 10^{-2} 1 / \mathrm{s}$ (decay time $\sim 20$ s) in the presence of a typical mesospheric temperature of $135 \mathrm{~K}$ (Vondrak et al., 2006a). Because of this rather short lifetime and because of the generally reduced concentration of the metal atoms in the presence of ice clouds, Vondrak et al. (2006b) concluded that a rather large fresh meteoroid (500 $\mu \mathrm{g}$ or larger) would be needed to make photoemission from ice a dominant charging process, and they further estimated that the probability for such an event would be on the order of $2 \%$. Hence, it appears unlikely that this effect is biasing our results, but it cannot be excluded based on the available data. 
Even though the error bars of derived particle radii and number densities are large, we might still compare our results to estimates of the vertical structure of these quantities from previous lidar, rocket, and satellite observations. Recently, Baumgarten and Fiedler (2008) presented an analysis of 8 years of lidar observations of particle size parameters and found an average increase of the particle size with decreasing altitude in fair agreement with the sporadic previous results from rockets and satellites reported by Gumbel and Witt (1998) and von Savigny et al. (2005) and the results shown in Fig. 10, respectively. The statistical analysis of Baumgarten and Fiedler (2008) revealed that the mean of the mean radius of an assumed Gaussian size distribution increases from $38.1 \pm 1.1 \mathrm{~nm}$ from $0.9 \mathrm{~km}$ above the brightness peak of the NLC to $58.5 \pm 2.5 \mathrm{~nm}$ at $0.6 \mathrm{~km}$ below the peak altitude. Corresponding number densities decrease from $133 \mathrm{~cm}^{-3}$ to $29 \mathrm{~cm}^{-3}$ from top to bottom of the layer. Comparing these values to the results presented in Fig. 10, we see that just like in all the previous cases the radius shows an overall increase with decreasing altitude while the number density decreases at the same time. However, it also reveals that the NLC that we launched into was rather special with a much larger particle number density and smaller radii than seen on average. Clearly, however, many more such measurements with significantly reduced errors would be needed in order to draw conclusions on the general vertical structure of NLC.

Finally, as an independent check of our values, we may also convert inferred number densities and radii to lidar backscatter coefficients. Doing so results in backscatter coefficients of $2-6 \times 10^{-10} \mathrm{~m}^{-1} \mathrm{sr}^{-1}$. This can be compared to the values reported by the ALOMAR RMR lidar before the actual ECOMA launch (see Fig. 3 and Baumgarten et al., 2009) which show slightly smaller values of about $2-3 \times 10^{-10} \mathrm{~m}^{-1} \mathrm{sr}^{-1}$. However, given the rather large uncertainties of the inferred number densities and radii (see Fig. 10), we regard this small difference as not significant. Unfortunately, we also have to note that a direct comparison of our derived ice particle radii to radii derived from a scattering angle analysis of the photometer measurements onboard the same payload is not available because of technical problems with the onboard magnetometers and consequently missing precise attitude information.

In summary, our analysis seems to point at a very localized structure in an inhomogeneous cloud and suggests that instruments with either large observational volumes and/or large sampling times might miss such features. However, a possible systematic overestimate of our derived ice volumes cannot be completely excluded.

\section{Conclusions}

In the current manuscript we presented in situ observations of mesospheric ice particles with a new particle detector which combines a classical Faraday cup with a new technique rely- ing on the active photoionization of particles and subsequent detection of photoelectrons. The rocket was launched into a decaying PMSE structure as revealed by the local ALWIN radar, i.e., the layer originally extended from $82-88 \mathrm{~km}$, but at the time of our launch had disappeared except for two narrow weak layers at $\sim 83$ and $87 \mathrm{~km}$. Interestingly, the particle observations from both the ECOMA particle detector as well as the onboard photometer measurements revealed the presence of (charged) ice particles throughout the original altitude range of the PMSE layer, i.e., also at those altitudes where the PMSE had already disappeared. Our simultaneous absolute electron density observations from a Faraday rotation experiment show that the reason for this is that the electron density at the altitudes between the two remaining maxima had decayed to a value below a threshold value of a few hundred electrons $/ \mathrm{cm}^{3}$ which was already earlier claimed to be a lower electron density limit for the existence of PMSE (Rapp et al., 2002). Our observations clearly show that the presence of charged ice particles is a necessary but not a sufficient condition for the presence of PMSE, i.e., additionally other requirements like a sufficiently large electron density and the presence of small scale structures (commonly assumed to be caused by turbulence) need to be satisfied.

The direct Faraday cup observations, which are only available on the upleg of the rocket flight, further showed a pronounced vertical structuring with largest signal in a narrow layer between 86.5 and $88 \mathrm{~km}$ altitude. The photoelectron currents are on the other hand available on both the upleg and downleg of the rocket flight and revealed a very strong horizontal structuring of the investigated ice layer, i.e., the very broad layer seen on upleg shrank to a narrow layer only $50 \mathrm{~km}$ apart on the downleg part of the rocket flight. Importantly, the qualitative structure of these photoelectron current profiles were remarkably closely matched by simultaneous photometer measurements on the same rocket thus demonstrating the reliability of this new technique.

We then showed that the measured photoelectron currents are a unique function of the ice particle volume density (and hence ice mass) within an uncertainty of only $15 \%$ and we derived corresponding altitude profiles of ice volume densities for upleg and downleg of the rocket flight. Derived values are in the range $2-8 \times 10^{-14} \mathrm{~cm}^{3} / \mathrm{cm}^{3}$ and are in general agreement with independent estimates from either satellite instruments or lidar measurements even though we note that our values are somewhat at the large side of those previous observations. Importantly, however, none of these alternative techniques reaches a comparable spatial resolution such that the rather large values reported here could indicate that the spatial sampling inherent to these other techniques leads to an undersampling of the local ice mass distribution. Finally, we also estimated particle radii and number densities from a combination of both the Faraday cup measurement and the photoelectron measurement. Resulting values are in the range $20-40 \mathrm{~nm}$, and $400-1400 \mathrm{~cm}^{-3}$. These values are, however, significantly more uncertain than our ice volume 
density estimate because further assumptions must be made which cannot be verified by our own or independent measurements on the same rocket.

Acknowledgements. The ECOMA project is sponsored by the German Space Center under DLR-grant 50OE0301. The Norwegian part of the project was funded by the Norwegian Space Centre as project ECOMA 2006 and the Research Council of Norway, as project 170848. The Austrian contribution was funded under grant 18560 of the Austrian Science Foundation (FWF). EISCAT is an international association supported by research organisations in China (CRIRP), Finland (SA), Germany (DFG), Japan (NIPR and STEL), Norway (NFR), Sweden (VR), and the United Kingdom (PPARC).

Topical Editor C. Jacobi thanks K. Lynch and another anonymous referee for their help in evaluating this paper.

\section{References}

Bailey, S. M., Merkel, A. W., Thomas, G. E., and Rusch, D. W.: Hemispheric differences in polar mesospheric cloud morphology observed by the Student Nitric Oxide Explorer, J. Atmos. Sol. Terr. Phys., 69, 1407-1418, 2007.

Baron, B., Hoover, D., and Williams, F.: Vacuum ultraviolet photoelectric emission from amorphous ice, J. Comp. Phys., 68, 19971999, 1978.

Baron, M.: EISCAT progress 1983-1985, J. Atmos. Terr. Phys., 48, 767-772, 1986.

Baumgarten, G. and Fiedler, J.: Vertical structure of particle properties and water content in noctilucent clouds, Geophys. Res. Lett., 35, L10811, doi:10.1029/2007GL033084, 2008.

Baumgarten, G., Fielder, J., Lübken, F.-J., and von Cossart, G.: Particle properties and water content of noctilucent clouds and their interannual variation, J. Geophys. Res., 113, D06203, doi:10.1029/2007JD008884, 2008.

Baumgarten, G., Fielder, J., Fricke, K. H., Gerding, M., Hervig, M., Hoffmann, P., Müller, N., Pautet, P.-D., Rapp, M., von Savigny, C., Singer, W., and Thomas, G. E.: The noctilucent cloud (NLC) display during the ECOMA/MASS sounding rocket flights on August 3, 2007: Morphology on global to local scales, Ann. Geophys., in press, 2009.

Bohren, C. F. and Huffman, D. R.: Absorption and scattering of light by small particles, Wiley, New York, 1983.

Brattli, A., Lie-Svendsen, Ø., Svenes, K., Hoppe, U.-P., Rapp, M., Latteck, R., and Friedrich, M.: The ECOMA 2007 rocket campaign: observations and numerical modelling of aerosol particle charging and plasma depletion in a PMSE/NLC layer, Ann. Geophys., in press, 2009.

Bremer, J., Hoffmann, P., Höffner, J., Latteck, R., Singer, W., Zecha, M., and Zeller, O.: Long-term changes of mesospheric summer echoes at polar and middle latitudes, J. Atmos. Sol. Terr. Phys., 68, 1940-1951, doi:10.1016/j.jastp.2006.02.012, 2006.

DeLand, M. T., Shettle, E. P., Thomas, G. E., and Olivero, J. J.: Latitude-dependent long-term variations in polar mesospheric clouds from SBUV version 3 PMC data, J. Geophys. Res., 112, D10315, doi:10.1029/2006JD007857, 2007.

do Couto, P. C., Cabral, B. J. C., and Canuto, S.: Electron binding energies of water clusters: Implications for the electronic properties of liquid water, 429, 129-135, doi:10.1016/j.cplett.2006.08.046, 2006.
Fan, Z. Y., Plane, J. M. C., Gumbel, J., Stegman, J., and Llewellyn, E. J.: Satellite measurements of the global mesospheric sodium layer, Atmos. Chem. Phys., 7, 4107-4115, 2007, http://www.atmos-chem-phys.net/7/4107/2007/.

Folkestad, K., Hagfors, T., and Westerlund, S.: EISCAT: An updated description of technical characteristics and operational capabilities, Radio Sci., 18, 867-879, 1983.

Friedrich, M., Torkar, K. M., Lehmacher, G. A., Croskey, C. L., Mitchell, J. D., Kudeki, E., and Milla, M.: Rocket and incoherent scatter radar common volume electron measurements of the equatorial lower ionosphere, Geophys. Res. Lett., 33, L08807, doi:10.1029/2005GL024622, 2006.

Gumbel, J. and Witt, G.: In situ measurements of the vertical structure of a noctilucent cloud, Geophys. Res. Lett., 25, 493-496, 1998.

Gumbel, J., Stegmann, J., Murtagh, D. P., and Witt, G.: Scattering phase funstions and particles sizes in noctilucent clouds, Geophys. Res. Lett., 28, 1415-1418, 2001.

Havnes, O. and Næsheim, L. I.: On the secondary charging effects and structure of mesospheric dust particles impacting on rocket probes, Ann. Geophys., 25, 623-637, 2007, http://www.ann-geophys.net/25/623/2007/.

Havnes, O., Trøim, J., Blix, T., Mortensen, W., Næsheim, L. I., Thrane, E., and Tønnesen, T.: First detection of charged dust particles in the Earth's mesosphere, J. Geophys. Res., 101, 1083910847, 1996.

Hedin, J., Gumbel, J., and Rapp, M.: On the efficiency of rocketborne particle detection in the mesosphere, Atmos. Chem. Phys., 7, 3701-3711, 2007, http://www.atmos-chem-phys.net/7/3701/2007/.

Hervig, M. E., Gordley, L. L., Stevens, M. H., III, J. M. R., Bailey, S. M., and Baumgarten, G.: Interpretation of SOFIE PMC measurements: Cloud identification and derivation of mass density, particle shape, and particle size, J. Atmos. Sol. Terr. Phys., in press, doi:10.1016/j.jastp.2008.07.009, 2009.

Horányi, M., Gumbel, J., Witt, G., and Robertson, S.: Simulation of rocket-borne particle measurements in the mesosphere, Geophys. Res. Lett., 26, 1537-1540, 1999.

Karlsson, B., Körnich, H., and Gumbel, J.: Evidence for interhemispheric stratosphere-mesosphere coupling derived from noctilucent cloud properties, Geophys. Res. Lett., 34, L16806, doi:10.1029/2007GL030282, 2007.

Kelley, M. C., Farley, D. T., and Röttger, J.: The effect of cluster ions on anomalous VHF backscatter from the summer polar mesosphere, Geophys. Res. Lett., 14, 1031-1034, 1987.

Latteck, R., Singer, W., and Bardey, H.: The ALWIN MST radar: technical design and performance, Proceedings of the 14th ESA Symposium on European Rocket and Balloon Programmes and Related Research, Potsdam, Germany (ESA SP-437), pp. 179184, 1999.

Latteck, R., Singer, W., Morris, R. J., Holdsworth, D. A., and Murphy, D. J.: Observation of polar mesosphere summer echoes with calibrated VHF radars at $69^{\circ}$ in the northern and southern hemispheres, Geophys. Res. Lett., 34, L14805, doi:10.1029/ 2007GL030032, 2007.

Lübken, F.-J.: Thermal structure of the Arctic summer mesosphere, J. Geophys. Res., 104, 9135-9149, 1999.

Lübken, F.-J. and Höffner, J.: Experimental evidence for ice particle interaction with metal atoms at the high latitude sum- 
mer mesopause region, Geophys. Res. Lett., 31, L08103, doi:10.1029/2004GL019586, 2004.

Megner, L., Khaplanov, M., Baumgarten, G., and Gumbel, J.: Particle size retrieval from noctilucent clouds at exceptionally high altitudes, Ann. Geophys., in press, 2009.

Plane, J. M. C., Murray, B. J., Chu, X., and Gardner, C. S.: Removal of meteoric iron on polar mesospheric clouds, Science, 304, 426428, 2004

Rapp, M. and Lübken, F.-J.: Modelling of particle charging in the polar summer mesosphere: Part 1 - general results, J. Atmos. Sol. Terr. Phys., 63, 759-770, 2001.

Rapp, M. and Lübken, F.-J.: Polar mesosphere summer echoes (PMSE): Review of observations and current understanding, Atmos. Chem. Phys., 4, 2601-2633, 2004, http://www.atmos-chem-phys.net/4/2601/2004/.

Rapp, M. and Strelnikova, I.: Measurements of meteor smoke particles during the ECOMA-2006 campaign: 1. particle detection by active photoionization, J. Atmos. Sol. Terr. Phys., in press, doi:10.1016/j.jastp.2008.06.002, 2009.

Rapp, M. and Thomas, G. E.: Modeling the microphysics of mesospheric ice particles: Assessment of current capabilities and basic sensitivities, J. Atmos. Sol. Terr. Phys., 68, 715-744, 2006.

Rapp, M., Gumbel, J., Lübken, F.-J., and Latteck, R.: Dregion electron number density limits for the existence of polar mesosphere summer echoes, J. Geophys. Res., 107(D14), doi:10.1029/2001JD001323, 2002.

Rapp, M., Hedin, J., Strelnikova, I., Friedrich, M., Gumbel, J., and Lübken, F.-J.: Observations of positively charged nanoparticles in the nighttime polar mesosphere, Geophys. Res. Lett., 32, L23821, doi:10.1029/2005GL024676, 2005.

Rapp, M., Thomas, G. E., and Baumgarten, G.: Spectral properties of mesospheric ice clouds: Evidence for nonspherical particles, J. Geophys. Res., 112, D03211, doi:10.1029/2006JD007322, 2007.

Robertson, S., Horányi, M., Knappmiller, S., Sternovsky, Z., Holzworth, R., Shimogawa, M., Friedrich, M., Torkar, K., Gumbel, J., Megner, L., Baumgarten, G., Latteck, R., Rapp, M., and Hoppe, U.-P.: Mass analysis of charged aerosol particles in NLC and PMSE during the ECOMA/MASS campaign, Ann. Geophys., in press, 2009.

She, C. Y., Williams, B. P., Hoffmann, P., Latteck, R., Baumgarten, G., Vance, J. D., Fiedler, J., Acott, P., Fritts, D. C., and Lübken, F.-J.: Simultaneous observation of sodium atoms, NLC and PMSE in the summer mesopause region above ALOMAR, Norway $\left(69^{\circ} \mathrm{N}, 12^{\circ} \mathrm{E}\right)$, J. Atmos. Sol. Terr. Phys., 68, 93-101, doi:10.1016/j.jastp.2005.08.014, 2006.
Strelnikov, B., Rapp, M., Strelnikova, I., Engler, N., and Latteck, R.: Small scale structures in neutrals and charged aerosol particles as observed during the ECOMA/MASS rocket campaign, Ann. Geophys., in review, 2009.

Strelnikova, I., Rapp, M., Strelnikov, B., Baumgarten, G., Brattli, A., Svenes, K., Hoppe, U.-P., Friedrich, M., Gumbel, J., and P.Williams, B.: Measurements of meteor smoke particles during the ECOMA-2006 campaign: 2. results, J. Atmos. Sol. Terr. Phys., in press, doi:10.1016/j.jastp.2008.07.011, 2009.

Thomas, G. E.: Mesopheric clouds and the physics of the mesopause region, Rev. Geophys, 29, 553-575, 1991.

Thomas, G. E., Olivero, J. J., Jensen, E. J., Schröder, W., and Toon, O. B.: Relation between Increasing Methane and the Presence of Ice Clouds at the Mesopause, Nature, 338, 490-492, 1989.

Turunen, T., Westman, A., Häggström, I., and Wannberg, G.: High resolution general purpose D-layer experiment for EISCAT incoherent scatter radars using selected set of random codes, Ann Geophys., 20, 1469-1477, 2002, http://www.ann-geophys.net/20/1469/2002/

von Savigny, C., Petelina, S. V., Karlsson, B., Llewellyn, E. J., Degenstein, D. A., Loyd, N. D., and Burrows, J. P.: Vertical variation of NLC particle sizes retrieved from Odin/OSIRIS limb scattering observations, Geophys. Res. Lett., 32, L07806, doi: 10.1029/2004GL021982, 2005.

von Zahn, U., von Cossart, G., Fiedler, J., Fricke, K. H., Nelke, G., Baumgarten, G., Rees, D., Hauchecorne, A., and Adolfsen, K.: The ALOMAR Rayleigh/Mie/Raman lidar: objectives, configuration, and performance, Ann. Geophys., 18, 815-833, 2000, http://www.ann-geophys.net/18/815/2000/.

Vondrak, T., Plane, J. M. C., and Meech, S. R.: Influence of submonolayer adsorption on the photoemission of the $\mathrm{Cu}(111) /$ water ice surface, J. Comp. Phys., 125, 224702, 2006a.

Vondrak, T., Plane, J. M. C., and Meech, S. R.: Photoemission from sodium on ice: a mechanism for positive and negative charge coexistence in the mesosphere, Phys. Chem. B Lett., 110, 38603863, 2006b.

Warren, S. G.: Optical constants of ice from the ultraviolet to the microwave, Appl. Optics, 23, 1206-1225, 1984.

Witt, G.: Height, structure and displacement of noctilucent clouds, Tellus, 14, 1-18, 1962.

Witt, G., Stegman, J., and Wood, H.: High-latitude noctilucent cloud and sodium layers near the mesopause, in: COSPAR Proceedings, Methods of measurements and results of lower ionosphere structure, Akademie-Verlag Berlin, 29, 431-445, 1974. 